\title{
EDUCAÇÃO DE USUÁRIOS E O DESENVOLVIMENTO DA COMPETÊNCIA INFORMACIONAL EM ESCOLAS PÚBLICAS
}

\section{LA EDUCACIÓN DE LO USUARIO Y DESARROLLO DE LA ALFABETIZACIÓN INFORMACIONAL ESCUELAS PÚBLICAS}

\author{
Luciane de Fátima Beckman Cavalcante - lucifbc@gmail.com \\ Doutora em Ciência da Informação pela Universidade Estadual Paulista \\ (UNESP). Professora Colaboradora da Universidade Estadual de Londrina.
}

Mayra Cervigni Bonalumi - maycb@ig.com.br Especialista em Gestão de Biblioteca Escolar pela Universidade Estadual de Londrina (UEL).

\section{RESUMO}

Introdução: A Sociedade da Informação fez surgir novas demandas em relação à informação e principalmente novas competências para lidar com todo o fluxo informacional existente. Neste cenário de mudanças, se evidencia o papel da biblioteca escolar como elemento importante ao desenvolvimento das competências informacionais.

Objetivo: A pesquisa teve como objetivo verificar como os colégios públicos estaduais de Londrina e sua biblioteca desenvolvem a competência Informacional nos alunos.

Metodologia: Foi realizada uma pesquisa qualitativa de cunho exploratório com a aplicação de um roteiro de entrevista semiestruturada ao responsável pela biblioteca do colégio e para a análise dos dados foi utilizado o método de Análise de Conteúdo.

Resultados: Foi constatado que as bibliotecárias das escolas pesquisadas exercem seu papel educativo, embora uma delas em menor intensidade. Tal função ocorre por meio de ações que visam ao desenvolvimento de habilidades informacionais e de atitudes positivas relacionadas à informação e da contínua luta para integrar a biblioteca ao sistema escolar e da formação continuada visando o melhor atendimento aos usuários.

Conclusões: Embora não exista um programa institucional voltado ao desenvolvimento da competência informacional ambas as bibliotecas pesquisadas realizam ações voltadas para 0 desenvolvimento de atitudes, habilidades e entendimento de conceitos relacionados ao universo informacional por meio de atividades de leitura e, em menor grau, de pesquisa. 
Palavras-chave: Competência Informacional. Educação de Usuário. Biblioteca Escolar. Bibliotecário escolar.

\section{INTRODUÇÃO}

A Era da informação exige cada vez mais profissionais capacitados para usufruir com eficiência e eficácia dos fluxos informacionais. Devido a estas constantes transformações sociais e culturais, as bibliotecas e os bibliotecários redimensionaram suas missões e funções, principalmente as que estão ligadas à área da educação, como a biblioteca universitária e a escolar. A biblioteca escolar passou a ter, além da missão de organizar e preservar os suportes documentais para atender aos docentes e discentes, a missão de difundir a informação e o conhecimento através da integração com a comunidade docente nos projetos de incentivo à leitura e na pesquisa escolar.

Com a nova missão, o bibliotecário escolar passou a ser um educador/orientador que deve desenvolver nos seus usuários o entendimento dos conceitos associados à informação e seu universo, ou seja, as atitudes e habilidades necessárias para navegar com eficiência e eficácia no complexo ambiente informacional atual. Ao processo de desenvolvimento destas habilidades, atitudes e valores dá-se o nome de competência Informacional.

Para atender às demandas advindas da Sociedade da Informação as escolas precisaram mudar suas metodologias didáticas centradas no professor para metodologias centradas no aluno. Estas novas metodologias enfatizam o aprendizado ao longo da vida e o aprender a aprender através de projetos e pesquisas.

Neste cenário, por ser um ambiente com uma multiplicidade de informações, o bibliotecário escolar além de organizar os recursos e serviços da biblioteca também possui a função de educador/orientador. É o bibliotecário, como orientador, que auxilia os alunos a desenvolverem suas habilidades de busca e uso das informações, em todos os formatos e meios, para gerarem novos conhecimentos, resolverem um problema, tomarem uma decisão, além de atitudes e valores em relação à informação.

A biblioteca também é responsável, assim como a escola, por incutir nos aprendizes atitudes e valores que os farão cidadãos mais críticos e conscientes dos seus direitos e deveres para com o outro, com o Estado e a Sociedade. Face ao exposto 
apresenta-se o seguinte questionamento: a biblioteca escolar contribui para o desenvolvimento das competências informacionais requeridas pela atual sociedade?

Dentre todos os elementos abarcados pela competência informacional na Biblioteconomia e Ciência da Informação tem-se a educação de usuários. A educação de usuários tem seu foco em programas realizados pelas bibliotecas para motivar e usar as instituições informativas, assim como, orientar seus usuários a percorrer o universo informacional, que está cada vez mais complexo. A Competência Informacional com foco na educação de usuários visa habilitar as pessoas a lidarem melhor com o grande volume de informações e com as várias mídias e formatos onde estas informações são veiculadas.

Pelo exposto a pesquisa teve como objetivo: analisar como os colégios Públicos Estaduais de Londrina e suas bibliotecas desenvolvem a competência informacional nos alunos.

\section{BIBLIOTECA ESCOLAR: COMPETÊNCIA INFORMACIONAL E EDUCAÇÃO DE USUÁRIOS}

As demandas advindas da Sociedade da Informação implicam que o sistema educacional forme pessoas com novas habilidades, atitudes e valores em relação à informação, ou seja, o sistema educacional deve formar aprendizes competentes informacionalmente. Bibliotecários escolares e professores são os profissionais capacitados para este fim. O bibliotecário além de ter a função de implementar e organizar as bibliotecas escolares possui também a função educativa e pedagógica e de mediador da informação.

Como mediador, o bibliotecário não é responsável somente pela gestão da biblioteca, organização e guarda da coleção, gestão dos recursos financeiros, materiais e humanos, mas também possui uma função educativa. Embora o exercício da função educativa pelo bibliotecário seja de suma importância, Campello (2009) em sua tese explica que mesmo que esta função esteja sendo estudada no Brasil desde a década de 60 ela não é colocada em prática pelos bibliotecários. Para deixar de ser visto somente como um organizador, o bibliotecário escolar deve assumir uma postura ativa com relação a sua função educativa e pedagógica. 
Nesta função educativa, o bibliotecário é um educador com o papel de servir como mediador entre o universo informacional e o usuário, mesmo que os outros atores do sistema educacional não o vejam desta forma, pois é responsável por promover a utilização da biblioteca e do seu acervo, a promoção da leitura, à formação do leitor, o uso adequado das tecnologias de comunicação e informação (TIC) na educação voltada para a aprendizagem contínua e fomentar a prática da competência informacional tanto nos alunos quanto nos outros atores do sistema educacional.

Como mediador, o bibliotecário deve estar sempre atualizado em relação às novas fontes informativas para melhor exercer seu papel de mediador e querer aprender continuamente. O bibliotecário escolar deve estar atento à questão da leitura, uma vez que ao atuar com a mediação de leitura, o bibliotecário é responsável por organizar campanhas que incentivem a leitura de diferentes gêneros literários e planeje atividades que motivem o apreço a diversidade cultural, tais como: exposições de fotos, pinturas, esculturas; feiras de artesanato; oficinas de música, saraus musicais e literários etc.

É importante que neste processo haja interação entre o bibliotecário e professor, entre biblioteca e escola para que a mediação de fato aconteça. $O$ aprofundamento desta integração ocorre quando o bibliotecário escolar assume o papel de educador por meio das funções educativa e pedagógica. A postura ativa, adquirida por meio das funções educativa e pedagógica, pode ser demonstrada através da colaboração bibliotecárioprofessor na elaboração de projetos de aprendizagem que estejam em acordo com as diretrizes pedagógicas da escola a qual provavelmente visa ao desenvolvimento das competências informacionais dos aprendizes. Cabe ressaltar que por meio de ações voltadas à educação de usuários, o bibliotecário pode exercer o seu papel educativo no desenvolvimento de habilidades voltadas ao melhor aproveitamento das informações e por consequência contribuir à aprendizagem dos usuários da biblioteca escolar, por meio da educação de usuários.

As ações formais de educação de usuário surgiram nos Estados Unidos da América (EUA) no inicio do século XX, pois os bibliotecários americanos estavam preocupados em ensinar o uso das bibliotecas e suas coleções aos usuários que estavam iniciando no mundo da escrita e da leitura. Conforme Batista (2010, p. 24) "Utilizar uma biblioteca não significa apenas retirar livros, mas sim usufruir do seu espaço físico como um centro de convivência, para a pesquisa escolar, para a leitura e para aprender a desenvolver a autonomia na busca da informação." 
De acordo com Córdoba González (1998) citado por Ronchesel e Pacheco (2008, p. 35) a definição de educação ou capacitação de usuários é "[...] o de provê-los de conceitos e ferramentas que the serão úteis não somente às suas necessidades imediatas, mas também através de toda vida, tornando-os mais produtivos, reflexivos e capazes de explorar os recursos informacionais à sua disposição." Percebe-se que esta definição vai ao encontro com os elementos que englobam a competência informacional.

Com a expansão das tecnologias de informação e comunicação (TICs), das fontes informacionais, o acesso facilitado às informações, o surgimento da internet e o aumento da complexidade no momento de buscar, recuperar e usar informações, a prática da educação de usuário executada nas bibliotecas já não atendia as demandas informacionais dos usuários. Com isto percebido, bibliotecários norte-americanos começaram a estudar novas formas de atender a seus usuários em suas necessidades informacionais. O foco voltou-se ao aprender a aprender, o aprendizado ao longo da vida, o pensamento crítico, a resolução de problemas, o processo investigativo, o uso das tecnologias de informação e comunicação, além dos conteúdos dados nos cursos de educação de usuários. Assim o escopo da educação de usuários foi ampliado, sendo direcionado ao desenvolvimento da information literacy, ou competência informacional.

Dudziak (2003) em seu texto "Information Literacy: princípios, filosofia e prática" contextualiza e apresenta uma cronologia sobre o surgimento do conceito de Information Literacy. No Brasil, o assunto começou a ser estudado em 2000 e apenas por bibliotecários que já pesquisavam a função educativa da biblioteca, fontes de informação, educação de usuários, serviço de referência e pesquisa.

Atualmente, o tema é muito pesquisado e não está mais restrito à classe bibliotecária. Contudo, ainda não existe uma tradução para o termo "Information Literacy" e nem uma definição precisa. Os autores brasileiros também usam as denominações "Letramento Informacional", "Habilidade Informacional", "Competência em Informação", "Fluência Informacional", "Habilidades Informacionais", "Alfabetização Informacional".

Nos países nos quais este tema já alcançou certa maturidade, a Competência Informacional tornou-se um conceito presente e central nas políticas educacionais, como no documento "Information Power" da Associação Americana de Bibliotecas Escolares (AASL). No entanto, a implementação de programas que valorizem o desenvolvimento da Competência Informacional nos estudantes dependerá do processo educacional seguido pela escola e da efetiva integração da biblioteca no ambiente escolar. Para que esta 
integração seja efetivada, o estudo e exposição do conceito de competência informacional e das bases que deram origem a ele, como a educação de usuários, são necessários.

Professores, educadores e bibliotecários precisam ter noção do que seja este assunto e o que representa para que assim não oponham resistência à implementação de programas de desenvolvimento da competência informacional na escola. Estes programas mostram-se importantes para transformar o aprendiz em um competente usuário da informação capaz de identificar, buscar, organizar, interpretar, avaliar, utilizar e comunicar a informação, assim como mudar valores e atitudes a respeito da informação e da construção do conhecimento para a resolução de problemas e tomada de decisões.

Gasque (2012, p. 33) cita atividades de educação de usuários que desenvolvem as habilidades informacionais contidas no processo da competência informacional. Estas atividades são:

No caso dos conteúdos necessários para buscar e usar informação, mais do que conhecer a organização do material de referência, as normas da ABNT ou os mecanismos de buscas da internet, os indivíduos precisam, por exemplo, saber produzir bons textos acadêmicos, elaborar projetos e implementá-los, comparar dados para fazer bons investimentos. Se a competência a ser desenvolvida vincula-se ao acesso efetivo e eficiente da informação, as habilidades prováveis seriam, por exemplo, selecionar os métodos apropriados de pesquisas ou sistemas de recuperação para acessar a informação necessária, planejar estratégias de busca de informação, recuperar dados em sistemas de informação.

Existem textos que relatam experiências de atividades de educação de usuários aplicadas em bibliotecas escolares com vistas ao desenvolvimento da Competência Informacional dos estudantes. Um dos textos é de Marta Leandro da Mata ${ }^{1}$ e Helen de Castro Silva, com o titulo de "Biblioteca escolar e a aplicação da proposta da competência em informação no ensino fundamental" e o outro texto é de Maria Helena Souza Ronchesel $^{2}$ e Leandro Kingeski Pacheco, com o titulo de "Diretrizes para cursos a distância de capacitação de usuários em bibliotecas universitárias" que, apesar de tratar

\footnotetext{
${ }^{1}$ MATA, Marta Leandro da; SILVA, Helen de Castro. Biblioteca escolar e a aplicação da proposta da competência em informação no ensino fundamental. CRB-8 Digital, São Paulo, v. 1, n. 3, p. 28-39, dez. 2008. Disponível em: <http://revista.crb8.org.br/index.php/crb8digital/article/viewFile/17/17> Acesso em: 15 jun. 2013.

2 RONCHESEL, Maria Helena Souza; PACHECO, Leandro Kingeski. Diretrizes para cursos a distância de capacitação de usuários em bibliotecas universitárias. Revista Brasileira de Biblioteconomia e Documentação, Nova Série, São Paulo, v.4, n.2, p. 33-43, jul./dez. 2008. Disponível em: <http://rbbd.febab.org.br/rbbd/article/view/105/145>. Acesso em: 22 jul. 2013.
} 
da educação de usuários em âmbito universitário, apresenta uma proposta de curso de educação de usuários que pode ser adaptada para os usuários da biblioteca escolar.

Ao final da escolarização básica, o serviço de educação de usuários deverá formar alunos competentes no uso de centros e serviços de informação, na identificação de suas necessidades informativas, nas habilidades de acessar, buscar, selecionar, recuperar, organizar, usar e apresentar as informações, na socialização do conhecimento adquirido, na resolução de problemas e além de tudo transformar os aprendizes em cidadãos capazes de exercer o pensamento crítico e o aprendizado ativo e autônomo.

Hilleshein e Fachin (2000, p. 91) argumentam que "A Biblioteca Escolar é também elemento de ligação entre professor e aluno na elaboração das leituras e pesquisas, buscando sempre uma melhor metodologia de transmissão do conhecimento, influenciando o hábito da leitura e tornando o aluno mais crítico." Esta interação é o motivo da existência da biblioteca escolar e para que ela exista as atividades e serviços da biblioteca devem estar de acordo com as necessidades da comunidade, as diretrizes pedagógicas, o currículo, os projetos e atividades da escola e a missão e objetivos da escola.

Para que a biblioteca alcance os objetivos propostos e cumpra com sua missão é preciso que os bibliotecários estejam atentos às funções exercidas pela biblioteca escolar, como por exemplo, a função cultural, educativa e pedagógica. Ao passo que o bibliotecário dentre todas as suas atribuições, consiga exercer a função educativa de fato, ele se torna um educador/orientador.

As atividades de educação de usuários necessitam ser planejadas e distribuídas em módulos que seguirão uma sequência lógica que facilitará o progresso e continuidade no aprendizado dos usuários. As referentes atividades devem fazer parte permanentemente dos serviços oferecidos pela biblioteca escolar, pois são muitos e variados os resultados alcançados pela comunidade escolar, como por exemplo, o melhor aproveitamento dos produtos e serviços da biblioteca, a melhora no desempenho escolar, a socialização do individuo e exercício da cidadania.

Possobom (2006) citado por Michel (2011) evidencia a necessidade de sistematizar e institucionalizar práticas de educação permanente de usuários para que estes desenvolvam a Competência Informacional. São por meio destas ações que serão desenvolvidas as Competências Informacionais dos educandos e outros membros da comunidade escolar. Contudo, antes que isto ocorra é necessário que o bibliotecário 
escolar e os educadores saibam o que é Competência Informacional, as habilidades informacionais a serem desenvolvidas e o que é a educação de usuário na biblioteca escolar.

\section{PROCEDIMENTOS METODOLÓGICOS}

Tratou-se de uma pesquisa qualitativa de cunho exploratório. O método qualitativo geralmente é muito usado nas Ciências Humanas e Sociais, pois permite que o pesquisador investigue questões como o comportamento de um determinado grupo, a influência que ocorre sobre alunos e professores quando há mudanças nos paradigmas educacionais, etc. Conforme explica Creswell (2007, p. 186) as características do método qualitativo são:

1) a pesquisa qualitativa ocorre em cenário natural,

2) a pesquisa qualitativa usa métodos múltiplos que são interativos e humanísticos,

3) a pesquisa qualitativa é emergente em vez de estritamente préconfigurada,

4) a pesquisa qualitativa é fundamentalmente interpretativa.

Este método foi escolhido porque esta pesquisa pretendeu verificar um fenômeno social e educacional, o desenvolvimento da competência em informação dos alunos realizado em dois Colégios Públicos Estaduais do município de Londrina por meio de suas bibliotecas. De acordo com Cervo, Bervian e Silva (2010, p. 63-64) a pesquisa exploratória é:

[...] O passo inicial no processo de pesquisa pela experiência e um auxílio que traz a formulação de hipóteses significativas para posteriores pesquisas. A pesquisa exploratória não requer a elaboração de hipóteses a serem testadas no trabalho, restringindo-se a definir objetivos e buscar mais informações sobre determinado assunto de estudo. Tais estudos têm por objetivo familiarizar-se com o fenômeno ou obter uma nova percepção dele e descobrir novas idéias. [...] Recomenda-se a pesquisa exploratória quando há pouco conhecimento sobre o problema a ser estudado.

O universo da pesquisa foi constituído de duas escolas públicas estaduais do município de Londrina, que doravante serão nomeadas como Escola 1 e Escola 2 para fins de sigilo da pesquisa. A técnica para a coleta de dados foi a aplicação de um roteiro 
de entrevista semiestruturada direcionada ao bibliotecário. $O$ roteiro da entrevista (Apêndice A) foi constituído de questões abertas e fechadas. A formulação do roteiro da entrevista foi dividida em dois blocos: 1) perfil do bibliotecário e 2) desenvolvimento da competência informacional por meio de atividades de educação de usuários. Foi realizado um pré-teste em duas escolas públicas estaduais para averiguar a pertinência das perguntas da entrevista. Tanto a entrevista do pré-teste como a entrevista propriamente dita foram gravadas com o uso do software gravador de som do Windows 7. As entrevistas foram transcritas e posteriormente analisadas por meio da técnica da análise de conteúdo.

Segundo Bardin ([197-?], p. 42) a análise de conteúdo é:

[...] um conjunto de técnicas de análise das comunicações visando obter, por procedimentos, sistemáticos e objectivos de descrição do conteúdo das mensagens, indicadores (quantitativos ou não) que permitam a inferência de conhecimentos relativos às condições de produção/recepção (variáveis inferidas) destas mensagens.

A análise de conteúdo é um método empírico composto por um conjunto de técnicas de análise das comunicações que tem por objetivos a ultrapassagem da incerteza e o enriquecimento da leitura e por funções a heurístico e a administração da prova (BARDIN, [197-?]).

A análise de conteúdo é dividida em três fases: pré-análise, exploração do material e tratamento dos resultados, a inferência e a interpretação. A pré-análise é a primeira etapa e segundo Bardin ([197-?], p. 95) é:

A fase de organização propriamente dita. Corresponde a um período de intuições, mas, tem por objectivo tornar operacionais e sistematizar as idéias iniciais, de maneira a conduzir a um esquema preciso do desenvolvimento das operações sucessivas, num plano de análise. Recorrendo ou não ao ordenador, trata-se de estabelecer um programa que, podendo ser flexível (quer dizer, que permita a introdução de novos procedimentos no decurso da análise), deve, no entanto, ser preciso.

De acordo com Bardin ([197-?]) a pré-análise é composta por cinco atividades não consecutivas e não estruturadas: 1) leitura 'flutuante', 2) escolha dos documentos, 3) formulação das hipóteses e objetivos, 4) referenciação dos índices e elaboração de indicadores e 5) preparação do material. 
A primeira técnica é usada com maior frequência na análise de conteúdo, e que foi utilizada nesta pesquisa, é a análise categorial. Neste tipo de análise, o texto é dividido em unidades de codificação ou índices (podem ser frases, palavras, etc.) que determinarão as categorias temáticas (indicadores) que serão utilizados na análise.

Para analisar o material é necessário codificá-lo. Para Bardin ([197-?], p. 103)

A codificação corresponde a uma transformação - efectuada segundo regras precisas - dos dados brutos do texto, transformação esta que, por recorte, agregação e enumeração, permite atingir uma representação do conteúdo, ou da sua expressão, susceptível de esclarecer o analista acerca das características do texto.

A organização da codificação envolve três escolhas: unidades de registro (recorte), regras de contagem (enumeração) e categorias (classificação e agregação). De acordo com Bardin ([197-?], p. 104) "Unidade de registro é o que deve ser codificado e corresponde a parte do conteúdo a considerar como unidade base, visando a categorização e a contagem frequencial. Estas unidades podem ser as palavras, frases, temas, etc." Caso as unidades de registro escolhidas apresentem ambiguidades, estas devem ser inseridas em uma unidade de contexto que retire a ambiguidade da unidade de registro permitindo a sua análise.

Ao se estabelecer a unidade de registro a ser utilizada também é necessário decidir sobre o modo de contagem (enumeração) que será usado. Há sete modos de contagem: presença, frequência, frequência ponderada, intensidade, direção, ordem e coocorrência. No momento da análise, pode-se usar mais de uma regra de contagem ao mesmo tempo.

Segundo Bardin ([197-?], p. 117) a categorização é:

[...] uma operação de classificação de elementos constitutivos de um conjunto, por diferenciação e, seguidamente, por reagrupamento segundo o gênero (analogia), com os critérios previamente definidos. As categorias, são rubricas ou classes, as quais reúnem um grupo de elementos (unidades de registro, no caso da análise de conteúdo) sob um título genérico, agrupamento esse efectuado em razão dos caracteres comuns destes elementos.

As categorias podem ser baseadas nos seguintes critérios: semântico, sintático, léxico e expressivo. Possui como objetivo a representação condensada e simplificada dos dados recolhidos. De acordo com Bardin ([197-?]) um conjunto de categorias bem construído segue os seguintes critérios: exclusão mútua, homogeneidade, pertinência, 
objetividade e fidelidade, produtividade. Ao serem analisados os dados possibilitaram a realização de inferências que apoiarão as conclusões da pesquisa.

\subsection{Caraterização do universo de pesquisa}

Escola 1 (Entrevistada 1): A Escola Paulo Freire é um colégio da rede pública estadual de ensino que está situado na cidade de Londrina, na região do Jardim Pizza. Possui 27 turmas totalizando 852 matrículas. Destas turmas, 14 são de Ensino Fundamental, com 456 matrículas; 10 são de Ensino Médio, com 325 matrículas e 3 são de atividades complementares, com 71 matrículas.

Escola 2 (Entrevistada 2): O Colégio Estadual Professora Maria José Balzanelo Aguilera - Ensino Fundamental e Médio pertence à rede pública estadual de ensino e está situado na cidade de Londrina, na região do Conjunto Cafezal. Possui 47 turmas totalizando 1254 matrículas. Destas turmas, 20 são de Ensino Fundamental, com 557 matrículas; 21 são de Ensino Médio, com 617 matrículas; 2 são de Atendimento Educacional Especializado, com 25 matrículas e 4 são de atividades complementares, com 55 matrículas.

A seguir tem-se a análise e discussão dos dados advindos da coleta de dados. Cabe ressaltar que a análise foi realizada por meio do método de Análise de Conteúdo: Assim foram estabelecidas duas grandes categorias: Perfil do Bibliotecário e Desenvolvimento da Competência Informacional por meio de Atividades de Educação de Usuários. As categorias mencionadas foram divididas em subcategorias, como é possível verificar nas análises.

\section{ANÁLISE E DISCUSSÃO dOS RESULTADOS}

Todas as entrevistadas são bibliotecárias formadas. A entrevistada 1 trabalha na escola e na biblioteca há mais de cinco anos e a entrevistada 2 trabalha nesta escola e em sua biblioteca somente há um ano.

\subsection{Análise: Categoria Desenvolvimento da Competência Informacional por meio de Atividades de Educação de Usuários}

Sub Categorias: Bibliotecário como educador, Conhecimentos necessários ao bibliotecário educador, Conhecimento sobre Competência Informacional. 
As entrevistadas 1 e 2 veem-se como educadoras. Em suas falas, observou-se que ambas enfatizam a importância de uma biblioteca escolar participando ativamente do cotidiano da escola com seus produtos, serviços, atividades e acervo. Em suas falas também se notou a importância da integração biblioteca - sala de aula para a efetiva participação do bibliotecário como educador. Estas posições adotadas pelas bibliotecárias encontram respaldo na literatura sobre biblioteca escolar e funções do bibliotecário escolar.

Atualmente, na literatura da área, os autores pessoais, como Fachin e Hilleshein; Gasque, Kulhtlau entre outros, e institucionais, como a IFLA/UNESCO (2005) com o Manifesto e as Diretrizes sobre biblioteca escolar, defendem que a biblioteca escolar é um centro de recursos de aprendizagem que deve ser considerado ao serem formuladas as políticas educacionais, a missão, os objetivos, o currículo e o projeto político pedagógico.

O bibliotecário escolar estará atuando como um educador - mediador ao realizar atividades culturais as quais fomentam a aprendizagem e atividades que transformam o ambiente da biblioteca em um local onde a socialização é incentivada. Ambas as entrevistadas atuam como bibliotecárias mediadoras, que é um requisito para os bibliotecários atuantes na sociedade da aprendizagem, e possuem uma postura proativa ao planejar e implantar atividades que visam fomentar o aprendizado, a leitura e a pesquisa. Estas atividades são feitas pela biblioteca e quando realizadas pela escola contam com o apoio da biblioteca.

Com relação à subcategoria "Conhecimentos necessários ao bibliotecário educador" a entrevistada 1 sugeriu que os bibliotecários que trabalham em bibliotecas de escolas, além dos conhecimentos do curso de Biblioteconomia ou Ciência da Informação deveriam ter conhecimentos da área educacional e de matérias de um curso de licenciatura, como didática. A entrevistada 2 observou que o bibliotecário atuante em escolas deve estar sempre atualizado em relação às notícias, tecnologias, acontecimentos nacionais e mundiais e também ter um conhecimento geral sobre as culturas e conhecimentos humanos.

As respostas de ambas estão em sintonia com a literatura consultada, contudo, a literatura também aborda outros conhecimentos que um bibliotecário escolar deve possuir, como: a) entender o conceito de biblioteca escolar; b) conhecer e executar os seus deveres; c) conhecer os estágios de desenvolvimento das pessoas; d) estar consciente do nível de compreensão dos usuários em relação ao universo informacional; 
e) habilidades comunicativas; f) compreender a diversidade cultural selecionando e disponibilizando informações específicas para os professores; g) conhecer as modernas metodologias de ensino e teorias educacionais; h) ter domínio do acervo, de como acessar os seus itens tornando disponível as informações à comunidade que atende; i) estudar a literatura, as teorias da leitura, a oralidade (Mediação Oral da Literatura), formas de produção, organização e comunicação do conhecimento; j) ensino das habilidades de uso e apresentação da informação a comunidade escolar; k) investigar as TIC, principalmente a internet para poder ensinar aos usuários como realizar pesquisas em fontes eletrônicas, como apresentar e comunicar informações eletronicamente; I) conhecimentos gerenciais e de marketing que são demonstrados por meio de atividades gerenciais como os relatórios, a liderança de equipes, a realização de projetos, a construção de parcerias e o desejo da formação continuada; m) ser leitor ativo; n) viabilizar o acesso à informação em seus diferentes suportes; o) conhecer as políticas públicas para o livro e a leitura; p) estabelecer relações afetivas com o leitor.

Em relação à subcategoria "Conhecimento sobre Competência Informacional" tanto a entrevistada 1 como a 2 mencionaram terem conhecimento sobre o assunto. Nesta subcategoria, elas disseram que o bibliotecário escolar deve possuir um conhecimento geral sobre todas as áreas do conhecimento; entender e usar as tecnologias existentes; buscar a formação continuada e ser competente informacionalmente, ou seja, ter desenvolvido as habilidades de identificar suas necessidades; buscar; acessar; interpretar; avaliar; organizar e usar a informação bem como entender e aplicar as habilidades referidas acima, as atitudes e ideias referentes à informação para a resolução de problemas, tomada de decisões e aprendizado independente e contínuo.

O exposto está em concordância com o pensamento de Belluzzo (2008), Dudziak (2003), Gasque (2012); ILFA/UNESCO (2005). Dudziak (2003) e Campello (2009), autores que além de conceituar a competência informacional também estudaram os elementos inerentes a este desse conceito como: o processo investigativo; o aprendizado ativo; o aprendizado independente; o pensamento crítico; o aprender a aprender; o aprendizado ao longo da vida.

O bibliotecário é o principal responsável por introduzir o processo da competência informacional, que é um processo de aprendizagem vinculado ao universo informacional, no planejamento curricular da escola em que trabalha e, é também em conjunto com os 
professores, o responsável por transmitir aos estudantes as habilidades, atitudes e ideias em relação à informação que os transformarão em competentes usuários da informação.

\subsection{Análises: Categoria Desenvolvimento da Competência Informacional por meio de Atividades de Educação de Usuários}

Subcategorias: Acesso e uso, Construção do conhecimento pautados na ética e responsabilidade social, Necessidades de informação dos usuários, Compartilhamento do Conhecimento Produzido, Normalização dos trabalhos e formas de apresentação, Construção dos processos de busca e recuperação de informações, Organização da informação.

Com referência à subcategoria "acesso e uso", a entrevistada 1 relatou que os serviços técnicos não são a principal prioridade da biblioteca, mas mesmo assim, o acervo é organizado e isto permite o planejamento e execução de atividades que incentivam o uso da biblioteca e apoiam o processo de aprendizagem dos alunos. Há uma estreita parceria entre a biblioteca e os professores, o que facilita a consecução das atividades de leitura e pesquisa, com a bibliotecária expondo e orientando sobre a correta utilização da biblioteca e das fontes tanto impressas quanto eletrônicas.

A entrevistada 2 narrou que, além da orientação presencial e individual, faz uso das redes sociais, por meio do facebook, para realizar e divulgar atividades de leitura. A orientação sobre a pesquisa ocorre de forma presencial e individual com foco no uso das fontes de informação e a apresentação dos trabalhos. Houve um treinamento sobre as normas da Associação Brasileira de Normas Técnicas (ABNT) de apresentação e estruturação de trabalhos, contudo, não foi feito pela atual bibliotecária.

As ações relatadas acima objetivam que a comunidade escolar conheça a biblioteca, seu propósito, serviços oferecidos, organização, produtos e recursos disponibilizados para usá-la em seu processo de aprendizagem. Tais ações também buscam desenvolver as habilidades informacionais necessárias para se tornarem competentes informacionalmente, ou seja, em relação ao acesso e uso, procura desenvolver a capacidade de identificar, acessar e avaliar as fontes informativas, tanto as impressas como as eletrônicas/digitais, de forma eficiente e eficaz.

Segundo Gasque (2012) quando as ações de educação de usuários são sistemáticas e planejadas, elas constituem-se como a primeira etapa do processo de desenvolvimento da Competência Informacional. 
$\mathrm{Na}$ subcategoria "construção do conhecimento pautados na ética e responsabilidade social", a entrevistada 1 argumentou sobre a construção do conhecimento por meio da pesquisa. Ela mencionou que instrui seus usuários a produzirem seus próprios trabalhos, assim como fazer a citação ou referência correta quando da utilização de dados que não são de sua autoria. Tal elemento visa combater a prática do plágio e ensinar sobre ética, responsabilidade com ideias alheias, a ter confiança e criatividade etc. Já a entrevistada 2 mencionou que trabalhou os conceitos de ética, responsabilidade social e sociabilidade é realizado por meio de um projeto de leitura chamado 'árvore do Conhecimento'. Ambas as atividades realizadas pelas bibliotecárias desenvolvem os conceitos base da competência informacional quais sejam: o pensamento reflexivo, o processo investigativo e o aprendizado ativo, independente e contínuo.

Na subcategoria "Necessidades de informação dos usuários", a entrevistada 1 relatou que apesar de não realizar uma pesquisa formal para traçar o perfil de sua comunidade, acompanha o dia a dia da escola, participa de todas as reuniões pedagógicas e da elaboração do currículo e do projeto político pedagógico. A entrevistada 2 também relatou que não faz nenhuma pesquisa e que está lutando para participar ativamente das reuniões pedagógicas, portanto, a única forma usada para determinar o perfil da comunidade é o contato do dia a dia com cada usuário que frequenta a biblioteca.

Conforme apontado por Belluzo (2005) o estudo de usuário é a primeira etapa que deve ocorrer ao se planejar os serviços e atividades da biblioteca, principalmente quando são atividades que visam ao aprimoramento do processo de aprendizagem dos usuários. Além disso, os bibliotecários devem usar estes estudos para formular e implantar formalmente atividades que visem à autonomia dos usuários em relação à própria descoberta de suas necessidades informativas e de leitura recreativa.

A entrevistada 1 não respondeu à subcategoria "Compartilhamento do conhecimento produzido" enquanto que a entrevistada 2 relatou um projeto de leitura referente à produção de minicontos. Neste projeto, os alunos escreviam os minicontos que depois foram expostos na biblioteca, além disso, alguns minicontos foram selecionados para fazer parte de outro projeto da escola que, ao final, teve como resultado a produção de um livro. 
Denota-se que o projeto de leitura mencionado seguiu as premissas de uma atividade de educação de usuário, qual seja, facilitar e incentivar o acesso; a comunicação e a geração de novos conhecimentos, assim como também desenvolveu em seus participantes as habilidades de construir, usar e comunicar as informações geradas para um propósito específico considerando as questões éticas, sociais e culturais advindas desta ação. Com este projeto, também há a possibilidade do desenvolvimento do hábito da leitura e da sensibilização em relação às diferentes formas de expressão cultural. Ao serem sensibilizados para a apreciação dos diferentes aspectos culturais existentes, os usuários da biblioteca têm a possibilidade de se transformarem em aprendizes independentes que procurarão por vontade própria o auto-aprendizado.

$\mathrm{Na}$ subcategoria "Normalização dos trabalhos e formas de apresentação", a entrevistada 1 relatou que há uma intensa parceria com os professores no momento de planejar uma atividade de pesquisa e também ao planejar e executar as atividades de leitura. Nas atividades de pesquisa, professores e bibliotecária exercem funções definidas. O professor escolhe o tema e monta um roteiro de pesquisa junto com os alunos enquanto que a bibliotecária fornece um apoio orientando os alunos na construção da parte estrutural do trabalho, por exemplo, ensinando a como redigir referências bibliográficas padronizadas.

Já as atividades de leitura realizadas pela biblioteca, que também contam com a participação dos professores, visam à criação do hábito de ler e do desenvolvimento das habilidades comunicativas e de análise, assim como, o desenvolvimento do ato de pensar criticamente. A bibliotecária 2 também descreveu que a atividade de orientação quanto à normalização de trabalho acadêmico é individual, feita em conjunto com os professores, e assim como na biblioteca da entrevistada 1, cada profissional conhece e exerce sua função no momento de orientar os alunos na pesquisa. Contudo, a biblioteca da segunda entrevistada não tem um planejamento formal para esta atividade enquanto que a biblioteca da primeira entrevistada o tem. Destaca-se que para qualquer tipo de atividade a ser efetuada na biblioteca, é necessário planejamento prévio.

As ações de educação de usuários realizadas pelas bibliotecas são orientadas para o desenvolvimento de habilidades informacionais contidas no processo de desenvolvimento da competência Informacional e estão em acordo com o que é expresso na literatura da área. 
Segundo Córdoba González (1998) citado por Ronchesel e Pacheco (2008) as ações de educação de usuários possuem como objetivos instrumentalizar seus usuários com os conceitos e ferramentas do universo informacional necessária para satisfazer suas necessidades informativas e também torná-los mais produtivos, reflexivos e capazes de explorar os recursos informacionais à sua disposição.

$\mathrm{Na}$ subcategoria "Construção dos processos de busca e recuperação de informações", a entrevistada 1 relatou que quando novos alunos de sexto ano ingressam no colégio, eles são levados à biblioteca onde é explicado o funcionamento, os serviços oferecidos, normas, regulamentos, atividades, enfim, tudo que concerne à biblioteca e que é importante para eles. No decorrer do ano é demonstrado a estes alunos novatos como o acervo é organizado, como pesquisar nele e nas diferentes fontes impressas e eletrônicas e é incentivada a participação nas diferentes atividades de leitura literária que acontece na biblioteca.

A entrevistada 2 comentou que, no momento da pesquisa, orienta individualmente os alunos sobre a importância da confiabilidade da fonte e das informações nela contida; a estruturação dos trabalhos acadêmicos e da construção criteriosa da estratégia de busca para uma melhor recuperação de informações relevantes.

O relato da entrevistada 2 está em acordo com o que se apresenta na literatura sobre educação de usuários em que segundo Dias e Pires (2004, p. 37 apud BATISTA, 2010; AH TON e VALÉRIO, 1979 apud OTA, 1990) um processo de educação de usuários deve considerar o acesso, a comunicação e a geração de novas informações e para isso deve destinar aos usuários o conhecimento sobre o ciclo informacional; as formas de produção da informação; o conhecimento sobre as fontes informacionais e para o que cada uma pode servir; instrumentalizar sobre a organização dos sistemas e redes informacionais existentes no mundo; possibilitar conhecer, entender e usar os diferentes sistemas de busca e fornecer aos usuários a possibilidade de reconhecer suas necessidades informacionais e montar estratégias de busca e apresentação das informações adequadas tornando-o independente em relação à biblioteca.

Segundo a IFLA/UNESCO estas ações também os tornam conscientes das suas necessidades de informação e ativamente conectados ao mundo das ideias através da formulação de hipóteses, estratégias de buscas eficazes, organização e interpretação das informações unindo-as a um conhecimento preexistente.

Na subcategoria "Organização da informação", a bibliotecária da entrevista 1 falou 
que formalmente planeja visitas dos alunos e professores a biblioteca para demonstrar sua importância, funcionamento, organização e serviços e atividades oferecidas. Já a bibliotecária da entrevista 2 relatou que orienta a pesquisa individualmmente, assim como, o uso das fontes impressas e eletrônicas; ensina a organização da sua biblioteca para os alunos e orienta que existem outros locais, além desta biblioteca, que também guardam, organizam, disseminam informações e que atendem ao público.

As ações praticadas nas respectivas bibliotecas transformam os alunos em aprendizes independentes capazes de entenderem a organização física de ambientes informacionais; a frequentarem assiduamente ambientes ricos em cultura, assim desenvolvento atitudes positivas referentes as diversidades culturais, econômicas, políticas, religiosas etc. e a buscar por conhecimento; motivam o aprendizado contínuo; fomentam a curiosidade e criatividade pautados por valores como ética e respeito etc. Todas as ações realizadas pelas bibliotecas auxiliam no desenvolvimento da competência informacional.

\section{CONSIDERAÇÕES}

A competência informacional é um processo que depende em grande parte dos esforços e comportamentos dos alunos, entretanto, na escola é iniciado pelo bibliotecário em parceria com professores e outros educadores por meio de atividades que valorizam o desenvolvimento da aprendizagem, como por exemplo, os programas e ações de educação de usuários.

Educação de usuário é uma das bases dos programas de desenvolvimento da competência informacional visto que, na biblioteca escolar, engloba ações referentes à leitura e à pesquisa. Estas atividades objetivam, direta ou indiretamente, à expansão da aprendizagem dos alunos baseada nos conceitos chaves da competência informacional, como: o aprendizado ao longo da vida; o aprender a aprender; o aprendizado independente; o aprendizado ativo; o processo investigativo e o pensamento crítico.

A educação de usuários tem por princípio ativo a orientação quanto ao uso da biblioteca; o desenvolvimento das habilidades de busca e uso da informação e o incentivo em frequentar bibliotecas, enquanto que a competência informacional vai além, englobando elementos que visam à autonomia do sujeito na sua relação com a informação, o desenvolvimento do pensamento crítico. 
Pelo exposto, entende-se que para a implementação de programas de competência informacional, aos quais é almejado o desenvolvimento de habilidades, atitudes e conceitos vinculados ao universo informacional, é necessário, antes de tudo, a ressignificação da biblioteca escolar como centro socializador e de recursos de aprendizagem e também a plena integração da biblioteca e do bibliotecário ao sistema escolar, ou seja, o bibliotecário escolar precisa lutar para ser visto como um profissional que também possui funções educativas e que tem capacidade para exercê-las mesmo sem ter um conhecimento profundo de áreas como psicologia, pedagogia, didática, antropologia etc.

Nas duas escolas pesquisadas ambas as bibliotecárias exercem seu papel educativo, embora a entrevistada 2 exerça com menos intensidade que a bibliotecária 1 , por meio de ações que visam ao desenvolvimento de habilidades informacionais e de atitudes positivas relacionadas a informação, da contínua luta para integrar a biblioteca ao sistema escolar e da formação continuada visando o melhor atendimento aos usuários.

Quando o bibliotecário escolar é aceito como educador, ele participa do cotidiano escolar bem como do planejamento pedagógico e curricular da escola e com isso é capaz de planejar e executar melhor as atividades voltadas para o desenvolvimento da competência informacional, pois suas lições estarão em acordo com o que é dado em sala de aula e assim os alunos não ficarão perdidos ou achando o conteúdo ministrado desnecessário.

Mesmo não existindo um programa institucional de competência informacional ambas as bibliotecas pesquisadas realizam ações voltadas para o desenvolvimento de atitudes, habilidades e entendimento de conceitos relacionados ao universo informacional por meio de atividades de leitura e, em menor grau, de pesquisa. Por fim, espera-se que esta pesquisa possa contribuir para melhorar o entendimento dos conceitos de competência Informacional e educação de Usuários, bem como, a relação entre eles e a contribuição deles no progresso da aprendizagem dos alunos e até dos outros membros do sistema escolar. 


\section{REFERÊNCIAS}

BARDIN, Laurence. Análise de conteúdo. Tradução de Luís Antero Reto e Augusto Pinheiro. Lisboa: Edições 70, [197-?]. 225p.

BATISTA, Lisiane Ulguim. Ações de Educação de usuários desenvolvidas em bibliotecas de escolas particulares de Porto Alegre: estudo de caso. 2010. Trabalho de Conclusão de Curso (Graduação em Biblioteconomia) - Departamento de Ciência da Informação, Universidade Federal do Rio Grande do Sul, Porto Alegre, 2010. Disponível em: <http://www.lume.ufrgs.br/handle/10183/27832>. Acesso em: 23 ago. 2013.

BELLUZZO, Regina Célia Baptista. Como desenvolver a Competência em Informação (Cl): uma mediação integrada entre a biblioteca e a escola. CRB-8 Digital, São Paulo, v. 1, n. 2, p. 11-14, out. 2008. Disponível em:

<http://revista.crb8.org.br/index.php/crb8digital/article/viewFile/25/25>. Acesso em: 20 ago. 2013.

Competências na era digital: desafios tangíveis para bibliotecários e educadores. ETD - Educação Temática Digital, Campinas, v. 6, n. 2, p. 30-50, jun. 2005. Disponível em: <http://www.fe.unicamp.br/revistas/ged/etd/article/view/1655/1501 >. Acesso em: 30 jun. 2013.

CAMPELLO, Bernadete Santos. Letramento Informacional no Brasil: práticas educativas de bibliotecários em escolas de ensino básico. 2009. Tese (Doutorado em Ciência da informação) - Escola de Ciência da informação, Universidade Federal de Minas Gerais, Belo Horizonte, 2009. Disponível em: <http://www.bibliotecadigital.ufmg.br/dspace/bitstream/handle/1843/ECID7UUPJY/tesebernadetesantoscampello.pdf?sequence=1>. Acesso em: 17 jun. 2013.

CERVO, Amado L.; BERVIAN, Pedro A.; SILVA, Roberto da. Metodologia cientifica. 6. ed. São Paulo: Pearson Prentice Hall, 2010.

CRESWELL, John W. Projeto de pesquisa: métodos qualitativo, quantitativo e misto. Tradução de Luciana de Oliveira da Rocha. 2. ed. Porto Alegre: Artmed, 2007. 248p.Tradução de: Research design: qualitative, quantitative and mixed methods approaches.

DUDZIAK, Elisabeth Adriana. Information Literacy: princípios, filosofia e prática. Ciência da Informação, Brasília, v. 32, n. 1, p. 23-35, jan./abr. 2003. Disponível em: <http://www.scielo.br/pdf/ci/v32n1/15970.pdf>. Acesso em: 20 abr. 2013.

GASQUE, Kelley Cristine Gonçalves Dias. Letramento Informacional: pesquisa, reflexão e aprendizagem. Brasília: Editora FCI/UnB, 2012. Disponível em:

<http://repositorio.unb.br/bitstream/10482/13025/1/LIVRO_Letramento_Informacional.pdf> . Acesso em: 20 jun. 2013.

HILLESHEIM, Araci Isaltina de Andrade; FACHIN, Gleisy Regina Bories. Biblioteca escolar: relato de experiência. R. ACB: Biblioteconomia em Santa Catarina, v. 5, n. 5, 2000. Disponível em: <http://revista.acbsc.org.br/racb/article/view/349/413>. Acesso em: 12 jun. 2013. 
IFLA. Manifesto IFLA/UNESCO para biblioteca escolar. Tradução de Neusa Dias Macedo. São Paulo: IFLA, 2000. Disponível em: <http://archive.ifla.org/VII/s11/pubs/manifest.htm>. Acesso em: 15 jun. 2013.

Diretrizes da IFLA/UNESCO para biblioteca escolar. Tradução de Neusa Dias Macedo e Helena Gomes de Oliveira. São Paulo: IFLA, 2005. Disponível em: $<$ http://www.ifla.org/files/assets/school-libraries-resource-centers/publications/schoollibrary-guidelines/school-library-guidelines-pt_br.pdf>. Acesso em: 08 set. 2013.

MICHEL, Luciane. Competência informacional: um estudo de caso na biblioteca infantil do Centro de Ensino Médio Pastor Dohms. 2011. Trabalho de Conclusão de Curso (Graduação em Biblioteconomia) - Departamento de Ciência da Informação, Universidade Federal do Rio Grande do Sul, Porto Alegre, 2011. Disponível em: <http://www.lume.ufrgs.br/handle/10183/31149>. Acesso em: 23 ago. 2013.

OTA, Maria Elizabete de Carvalho. Educação de usuários em bibliotecas universitárias brasileiras: revisão de literatura nacional. R. bras. Bibliotecon. e Doe., São Paulo, v. 23, n. 1/4, p. 38-57, jan./dez. 1990. Disponível em: $<$ http://www.brapci.ufpr.br/documento.php?dd0=0000002795\&dd1=08af0 >. Acesso em: 22 jul. 2013.

\title{
Title
}

Users education and racing development in information literacy in public schools

\begin{abstract}
Introduction: The Information Society has raised new demands with regard to information and especially new skills to deal with all existing information flow. In this scenario changes, it is clear the role of the school library as an important element for the development of information literacy.

Objective: The study aimed to verify the state public schools of Londrina and its library Informational develop competence in students.

Methodology: a qualitative study of exploratory nature with the application of a semi-structured interview guide the person responsible for the school library was performed and to analyze the data we used the content analysis method.

Results: It was found that the librarians of the schools surveyed exercise their educational role, although one of them at a lower intensity. This function occurs through actions aimed at the development of information literacy and positive attitudes toward information and ongoing struggle to integrate the library to the school system and continuing education in the best service to users.

Conclusion: Although there is an institutional program focused on the development of information literacy both surveyed libraries carry out actions aimed at the development of attitudes, skills and understanding of concepts related to the informational universe through reading activities and to a lesser extent, research.
\end{abstract}

Keywords: Information literacy. User Education. School Library. School Librarian 


\section{Título}

La educación de lo usuario y desarrollo de la alfabetización informacional escuelas públicas

\section{Resumen}

Introducción: La Sociedad de la Información hizo surgir nuevas demandas en relación a la información y principalmente nuevas competencias para lidiar con todo el flujo informacional existente. En este escenario de cambios, se evidencia el papel de la biblioteca escolar como un elemento importante para el desarrollo de las competencias informacionales.

Objetivo: La pesquisa tiene como objetivo verificar cómo los colegios públicos estatales de Londrina y sus bibliotecas desarrollan la competencia informacional en los alumnos.

Metodología: Fue realizada una pesquisa cualitativa de naturaleza exploratoria con la aplicación de una guía de entrevista semiestructurada al responsable de la biblioteca del colegio, y para el análisis de los datos fue utilizado el método de Análisis de Contenido.

Resultados: Se encontró que los bibliotecarios de las escuelas encuestadas ejercen su función educativa, aunque uno de ellos a una intensidad menor. Esta función se produce a través de acciones dirigidas al desarrollo de la alfabetización informacional y las actitudes positivas hacia la información y la lucha en curso para integrar la biblioteca para el sistema escolar y la educación continua en el mejor servicio a los usuarios .

Conclusiones: A pesar que no exista un programa institucional dirigido al desarrollo de la alfabetización informacional, ambas bibliotecas pesquisadas realizan acciones dirigidas para el desarrollo de actitudes, habilidades y entendimiento de los conceptos relacionados al universo informacional por medio de actividades de lectura, y en menor grado, de pesquisa.

Palabras clave: Competencia Informacional. Educación del Usuario. Biblioteca Escolar. Bibliotecario Escolar.

Recebido em: 12.11 .2014

Aceito em: 22.12.2014 